\title{
Writing tremor: its relationship to benign essential tremor
}

\author{
T KACHI, JC ROTHWELL, JMA COWAN, CD MARSDEN \\ From the University Department of Neurology, Institute of Psychiatry and King's College Hospital Medical \\ School, De Crespigny Park, London, UK
}

SUMMARY Nine patients with tremor on writing and one patient with tremor only on swinging a golf club were investigated. None of the patients had any other neurological symptoms or signs. The frequency of the tremor ranged from 5 to $6 \mathrm{~Hz}$. Rapid passive supination or pronation of the forearm by a torque motor evoked a short burst of alternating tremor in seven patients. The tremor was improved by alcohol or propranolol in six patients. These characteristics of writing tremor (and of other isolated action tremors) suggest that it is a variant of benign essential tremor.

Tremor on writing occurs in many neurological illnesses, including Parkinson's disease, essential tremor, torsion dystonia, and spinocerebellar degenerations. Patients with these disorders have obvious difficulty with other actions of the hand, and they also exhibit diagnostic physical signs on examination. There are some patients, however, whose sole complaint is of a tremor when writing and who have no other neurological symptoms or signs. In a previous paper,' we reported the clinical and physiological features of a single patient with such a tremor, and designated it primary writing tremor. At the time, it was unclear whether this represented a novel entity, or was an isolated variant of benign essential tremor. Since then, there have been several other reports of patients with tremor only appearing on writing. ${ }^{3}$

In the present paper, nine patients with tremor which appeared principally on writing, and one patient with tremor which appeared on swinging a golf club have been investigated. Their clinical and electrophysiological characteristics have been compared to previous results in patients with typical essential tremor. We conclude that primary writing tremor, and similar isolated tremors on other motor actions, represent part of the spectrum of benign essential tremor.

Address for reprint requests: Prof CD Marsden, Dept of Neurology, Institute of Psychiatry, De Crespigny Park, London SE5 8AF, UK

Received 25 September 1984

Accepted 29 October 1984

\section{Methods}

The EMG was recorded using silver/silver chloride surface electrodes from biceps, triceps, pronator teres and finger flexors, and supinator teres and finger extensors. Signals were amplified and processed (Devices 3160 amplifiers with low and high frequency $3 \mathrm{~dB}$ points set at 80 and 2.5 $\mathrm{kHz}$ respectively, and Devices signal processors type 4010), then were collected and digitised by a PDP12 computer using programmes devised by Mr HB Morton. Sampling rate was $1 \mathrm{kHz}$ per channel.

Stretch reflexes were investigated in the wrist flexor muscles using a dc torque motor (Printed Motors type $\mathrm{G} 12 \mathrm{M})$. Subjects were seated comfortably with the forearm semipronated and strapped to a platform. This allowed movement only at the wrist, which was placed coaxial with the shaft of the torque motor. The fingers were encased in a rigid splint. The motor provided a steady extensor torque of $0.23 \mathrm{Nm}$ whilst subjects maintained a constant wrist position $\left(160^{\circ}\right.$ flexion) with reference to an oscilloscope display before them. At random intervals, between $3-4.5 \mathrm{~s}$, the torque was increased to $0.46,0.7$, or $0.93 \mathrm{Nm}$ in a random sequence. Average position (from a Bourns 2" servopotentiometer), velocity and rectified surface EMG responses (of 8 trials) from forearm flexor and extensor muscles were recorded. The duration of the reflex EMG responses was measured by visual inspection of the traces, and the size was expressed as a percentage of background levels of activity in control trials in which no torque change occurred.

In five patients, the effect on the writing tremor of a slow intravenous injection of propranolol was investigated. Between 1.7 and $2.0 \mathrm{mg}$ were given, the dose in each case being sufficient to cause a reduction in standing pulse rate to 60 . Informed consent was obtained. 
Table 1 Clinical and physiological features of 10 patients with primary writing tremor ( 9 cases) or golfer's tremor (1 case)

\begin{tabular}{|c|c|c|c|c|c|c|c|c|c|c|}
\hline Case & $J G$ & $B L$ & $T B$ & $L Y$ & $A M$ & $E W$ & $F S$ & $A S$ & $C B$ & $D T$ \\
\hline Age (years) & 65 & 29 & 63 & 61 & 43 & 58 & 63 & 24 & 62 & 29 \\
\hline & $\mathbf{M}$ & $\mathbf{M}$ & $\mathbf{M}$ & $\mathbf{F}$ & $\mathbf{M}$ & $\mathbf{M}$ & $\mathrm{F}$ & $\mathbf{M}$ & $\mathbf{M}$ & $\mathbf{M}$ \\
\hline Age of onset (years) & 61 & 21 & 59 & 51 & 31 & 33 & & & 55 & 25 \\
\hline Past history & 0 & Trauma* & 0 & 0 & 0 & Trauma $\dagger$ & Trauma & Meningitis & 0 & \\
\hline Family history & 0 & NK & & 0 & 0 & & & & 0 & \\
\hline Affected limb & RH & RH & RH & RH & $\mathbf{R H}$ & RH & RH & RH & RH & LH \\
\hline Tremor on writing & + & + & \multirow{2}{*}{\multicolumn{2}{|c|}{ clenching fist 0}} & + & & + & & + & \\
\hline Tremor on other action & 0 & 0 & & & 0 & shaving & 0 & screwdriver & r0 & golf-su \\
\hline Tremor induced by tendon tap & 0 & 0 & 0 & 0 & 0 & 0 & 0 & + & + & + \\
\hline Tremor induced by torque motor & + & + & 0 & 0 & + & + & 0 & + & + & + \\
\hline Minimal postural tremor & 0 & 0 & 0 & 0 & + & 0 & + & 0 & 0 & \pm \\
\hline Frequency of tremor $(\mathrm{Hz})$ & $5-6$ & $5-6$ & 6 & $5-6$ & $5-6$ & $5-6$ & 6 & 6 & 5 & $5-6$ \\
\hline Alternating contraction of antagonists & ts + & + & + or - & + & + & + & + & - or + & + & + \\
\hline Effect of alcohol & + & $?$ & & + & $?$ & $?$ & ? & + & $?$ & 0 \\
\hline $\begin{array}{l}\text { Effect of intravenous injection of } \\
\text { propranolol }\end{array}$ & + & ND & ND & + & ND & + & + & ND & ND & 0 \\
\hline $\begin{array}{l}\text { Effect of oral administration of } \\
\text { propranolol }\end{array}$ & + & ND & ND & + & ++ & ++ & + & + & ND & ND \\
\hline
\end{tabular}

RH = Right hand; LH = Left hand; NK = Not known; ND = Not done; ? = Not known because the patient did not often drink alcohol. $*=$ Injury to right forearm; $\dagger=$ Frequently hit on right hand; $\ddagger=$ Fracture of right 4 th metacarpal bone.

(a)

FF

FE

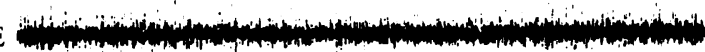

(c)

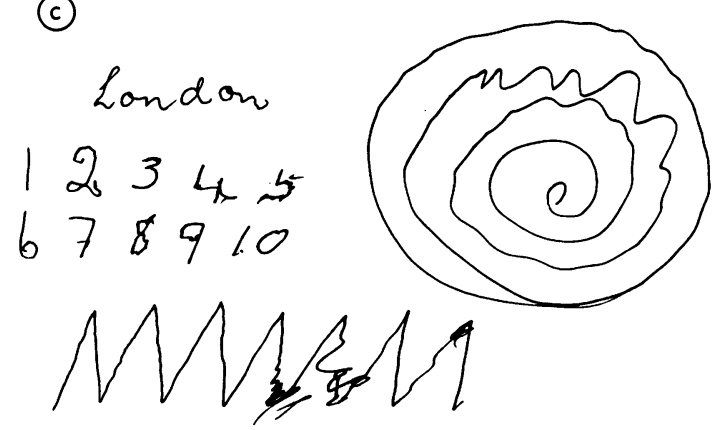

12345

(b)

FF + H (d)

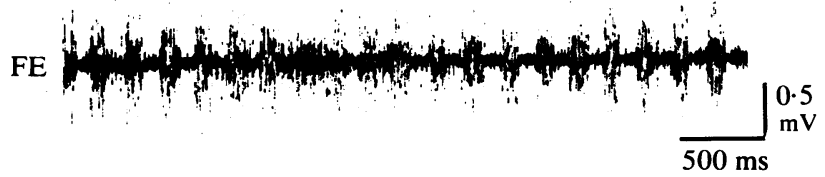

pronation

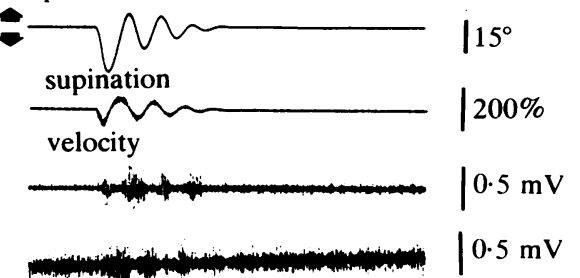

$\overline{500 \mathrm{~ms}}$

Fig 1 EMG records and samples of hand-writing and drawing in patient JG. A. EMG record from right arm held outstretched horizontally in front of body. No postural tremor is evident. B. EMG record from right arm when writing. Continuous rhythmic reciprocal grouped discharges at 5-6 Hz are evident in the finger flexors (FF) and finger extensors (FE). C. Samples of hand-writing and drawing with the affected right hand. D. EMG response to forced supination of the right forearm with the torque motor. A short burst of alternating tremor at 5-6 $\mathrm{Hz}$ was induced in finger flexors and extensors. 

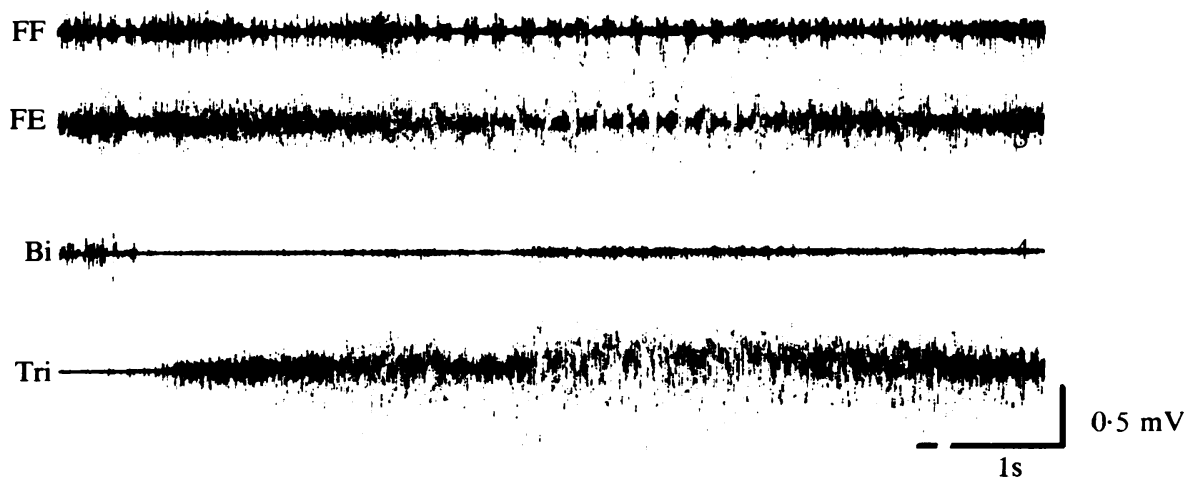

$\uparrow$

Fig 2 EMG record from left arm in patient DT with golfer's tremor. As he swings his golf club back (arrow indicates the beginning of back swing) alternating tremor appears at 5-6 $\mathrm{Hz}$ in finger fkxors (FF) and finger extensors (FE). No tremor was evident in biceps brachii (Bi) or triceps brachii (Tri).

\section{Clinical features}

The characteristics of the tremor and clinical details of the 10 patients are summarised in table 1. Patient AS is the same patient as reported in a previous paper.' In nine of the patients, tremor occurred most frequently on writing or drawing (fig 1). One other patient was a professional golfer, whose tremor in his left hand only appeared when he began a "backswing" (fig 2). In all cases, the principal feature was a rhythmic pronation/supination of the forearm, which in eight cases had the "sinusoidal" character of a true tremor; in the other two cases (AS and CB), the movement appeared more jerky. In these two patients, and in the golfer (DT), tremor could be provoked either by taps by a tendon hammer to supinate (AS and CB) or pronate (DT) the forearm. Although such tendon taps had no effect on any of the other patients, forced pronation or supination of the wrist using a torque motor produced tremor in seven of the ten patients (fig 1; table 1).

The cardinal feature of all the patients was the limited range of acions during which tremor was evident. In six cases, this was solely limited to the act of writing. In patient $\mathrm{CB}$ (and patient AS, who also had tremor on using a screwdriver) tremor only occurred on beginning to put pen to paper, disappearing when he started to write. Three other patients with writing tremor also noted some tremor in other tasks, including shaving and combing the hair (see table 1).

Only three patients had a very mild postural tremor of the outstretched arms, which was no more than that seen in many normal subjects. None of the patients had tremor at rest. No patient exhibited cerebellar signs, akinesia, rigidity, spasticity or any other neurological deficit except tremor.

Patient BL had lacerated his right forearm without nerve injury; shortly afterwards he noticed a tremor on writing, which gradually deteriorated over the next 8 years. EW had been hit on the right forearm frequently when he was playing cricket or hockey 5-6 years before he developed tremor. FS had fallen onto the palm of her right hand, fracturing the 5th metacarpal bone just before the tremor started. AS had suffered uncomplicated meningitis, from which he had completely recovered, 3 years before the sudden onset of tremor. No patient reported a family history of tremor.

Three patients noted that their tremor was improved by alcohol. Six patients did not imbibe. Patient DT had tried alcohol for the purpose of improving his tremor, but found it useless.

\section{Physiological studies}

The EMG in supinator teres and finger extensors, pronator teres and finger flexors, and to a lesser extent in biceps/triceps, showed rhythmic bursts at 5 to $6 \mathrm{~Hz}$ when the patients began to write or began to swing a golf club (figs 1 and 2 , and table 1). In patients AS, DT and CB these bursts faded away after continuing to write or to swing the club. The tremor alternated in agonist and antagonist muscles in 8 of the 10 patients. Patient AS, and occasionally patient TB, sometimes had co-contracting tremor.

Stretch reflexes of the wrist and finger flexor muscles were investigated in five patients. There was no 
Table 2 Latency, duration and size of stretch reflex in primary writing tremor

\begin{tabular}{|c|c|c|c|c|c|}
\hline & \multirow{2}{*}{$\begin{array}{l}\text { Size of stretch } \\
(\mathrm{Nm})\end{array}$} & \multicolumn{2}{|c|}{ Short latency (spinal) component } & \multicolumn{2}{|l|}{ Long latency component } \\
\hline & & $\begin{array}{l}\text { Primary writing tremor } \\
(N: 5)(\text { Mean } \pm S D)\end{array}$ & $\begin{array}{l}\text { Normal controls } \\
(N: 8)(\text { Mean } \pm S D)\end{array}$ & $\begin{array}{l}\text { Primary writing tremor } \\
(N: 5)(\text { Mean } \pm S D)\end{array}$ & $\begin{array}{l}\text { Normal controls } \\
(N: 8)(\text { Mean } \pm S D)\end{array}$ \\
\hline Latency & $\begin{array}{l}0.46 \\
0.70 \\
0.93\end{array}$ & $\begin{array}{l}30 \cdot 0 \pm 3 \cdot 61 \mathrm{~ms} \\
30 \cdot 8 \pm 4 \cdot 38 \\
29 \cdot 2 \pm 3 \cdot 56\end{array}$ & $\begin{array}{l}30 \cdot 8 \pm 3 \cdot 65 \mathrm{~ms} \\
27 \cdot 8 \pm 2 \cdot 76 \\
28 \cdot 1 \pm 2 \cdot 90\end{array}$ & $\begin{array}{l}55 \cdot 0 \pm 8 \cdot 19 \mathrm{~ms} \\
59 \cdot 4 \pm 7.64 \\
57 \cdot 8 \pm 8.04\end{array}$ & $\begin{array}{l}54 \cdot 0 \pm 5 \cdot 76 \mathrm{~ms} \\
52 \cdot 5 \pm 5 \cdot 93 \\
53 \cdot 6 \pm 5 \cdot 24\end{array}$ \\
\hline Duration & $\begin{array}{l}0.46 \\
0.70 \\
0.93\end{array}$ & $\begin{array}{l}17.8 \pm 4.55 \mathrm{~ms} \\
19.4 \pm 4.16 \\
15.4 \pm 3.36\end{array}$ & $\begin{array}{l}19 \cdot 0 \pm 6 \cdot 61 \mathrm{~ms} \\
22 \cdot 3 \pm 4 \cdot 78 \\
20 \cdot 8 \pm 5 \cdot 55\end{array}$ & $\begin{array}{l}45 \cdot 2 \pm 9 \cdot 36 \mathrm{~ms} \\
44 \cdot 8 \pm 6 \cdot 91 \\
54.6 \pm 10 \cdot 67\end{array}$ & $\begin{array}{l}44 \cdot 0 \pm 8 \cdot 94 \mathrm{~ms} \\
47 \cdot 5 \pm 6 \cdot 78 \\
47 \cdot 6 \pm 5 \cdot 32\end{array}$ \\
\hline Size & $\begin{array}{l}0.46 \\
0.70 \\
0.93\end{array}$ & $\begin{array}{l}153 \cdot 2 \pm 36.0 \% \\
213.7 \pm 72.0 \\
224.7 \pm 57.9\end{array}$ & $\begin{array}{l}200 \cdot 0 \pm 52 \cdot 0 \% \\
247 \cdot 1 \pm 47 \cdot 1 \\
291 \cdot 2 \pm 103 \cdot 9\end{array}$ & $\begin{array}{l}250 \cdot 4 \pm 86 \cdot 5 \% \\
375 \cdot 5 \pm 151 \cdot 3 \\
487 \cdot 0 \pm 189.5\end{array}$ & $\begin{array}{l}394 \cdot 0 \pm 150 \cdot 8 \% \\
605 \cdot 5 \pm 239.4 \\
753.4 \pm 270.9\end{array}$ \\
\hline
\end{tabular}

The size of the stretch reflex component was expressed as a percent of baseline control EMG activity.

(a)

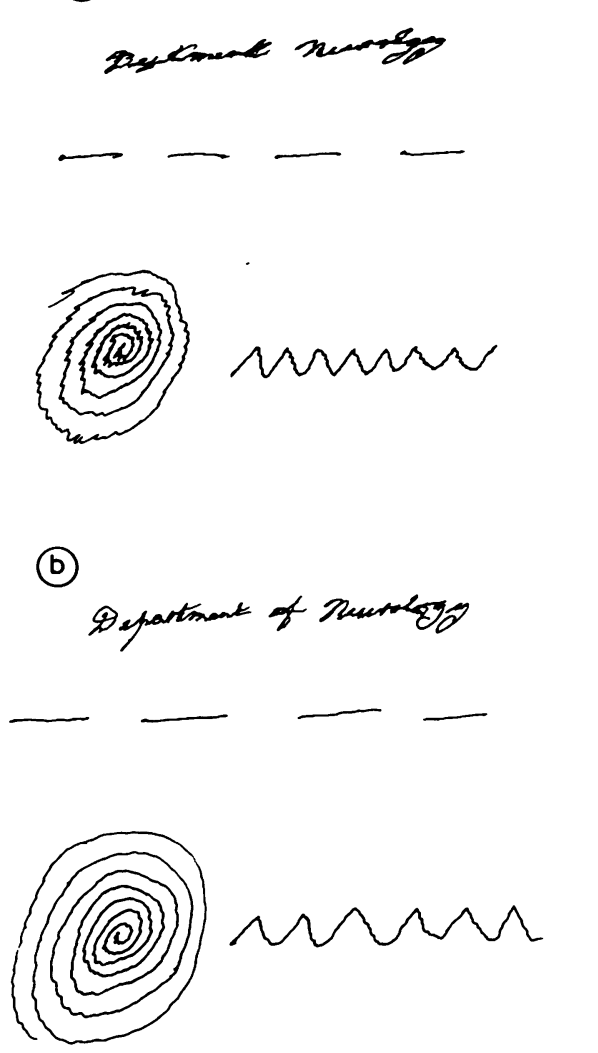

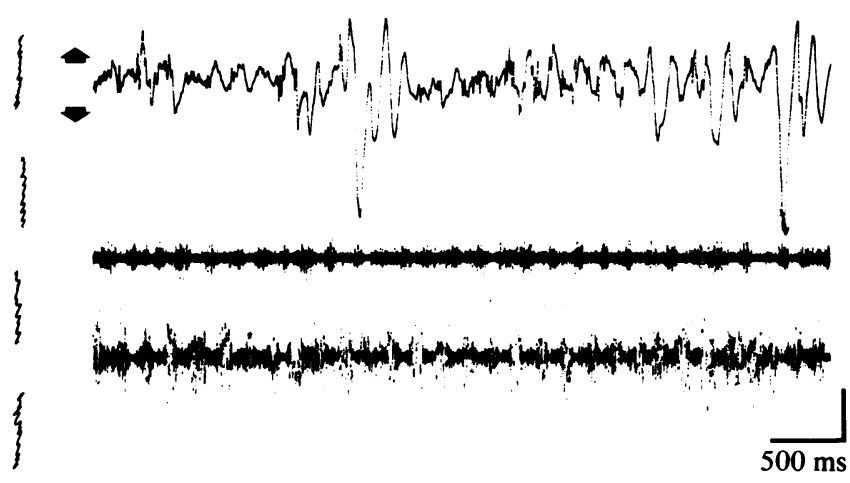
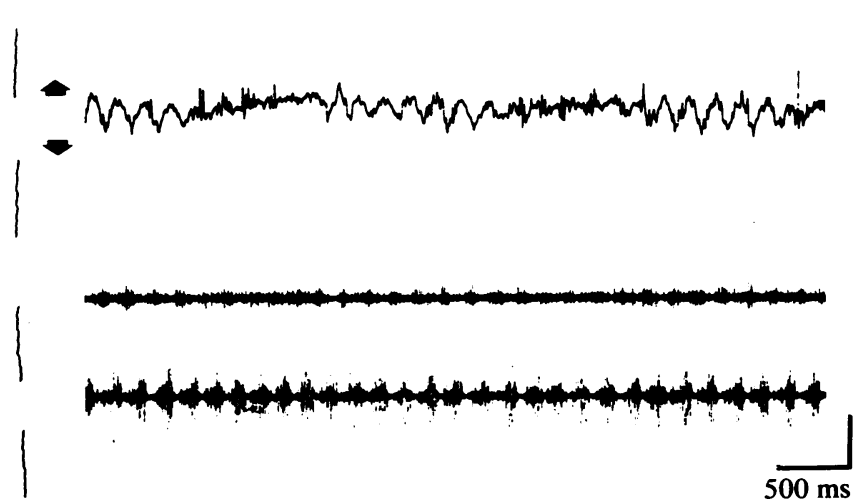

Fig 3 The effect of propranolol on tremor in patient $L Y$. Writing and drawing with the right hand before $(A)$ and 4 minutes after $(B)$ intravenous injection of $1.7 \mathrm{mg}$ propanolol. EMG from finger flexors (FF) and finger extensors (FE) was recorded at the same time (right). An accelerometer was placed on the dorsum of the wrist over the second metacarpal bone to record movement of the wrist (Acc.). Writing tremor was improved and the amplitude of the EMG bursts was decreased after injection of propranolol. 
difference between the size, duration, or latency of either the long of the short latency (spinal) components of the stretch reflex in these patients as compared with a control group of age-matched normal subjects (table 2 ).

\section{Effect of propranolol on tremor}

The effect of an intravenous injection of propranolol was investigated in five patients (table 1). Immediately before the injection, and several times after, each patient was asked to write his name, the name of the department, draw several vertical and horizontal lines and an Archimedes spiral. Patient DT was required to swing his golf club before and after injection. The EMG was recorded during all these tasks.

In four of the patients, writing was obviously improved, and the amplitude of the tremor bursts in the EMG decreased after the injection (fig 3). The improvement was most marked 3-5 min after injection, although in some patients it lasted for up to 1 hour. The frequency of the tremor was unaffected. Patient DT did not note any improvement in his golfing tremor after the injection.

Six patients took $120-240 \mathrm{mg}$ propranolol orally per day (table 1). All these patients reported that this improved their tremor.

\section{Discussion}

Primary writing tremor was first described ' in a single patient who was included in the present study. In his case, tremor was seen principally when he started to write, or when he took his pen off the page at the end of a line. The tremor was co-contracting and jerky in character, and could be provoked by tendon taps to the wrist. Patients CB and DT of the present study had a very similar tremor, except that in DT the special action was swinging a golf club rather then writing. The other seven patients had tremor on writing, but their tremor lasted as long as they wrote. It was not jerky, and could not be provoked by tendon taps, although rapid wrist pronation/supination with a torque motor did produce tremor in four of them. This latter type of tremor appears to be very similar to that of other patients with tremor on writing reported in the literature. ${ }^{23}$

Two questions arise. Firstly, do all the patients in the present study have the same form of tremor, or is the jerky, tap-provoked tremor (which was originally designated "primary writing tremor") a different entity from the continuous tremor that persists throughout the act of writing? Secondly, is this writing tremor related in any way to other disorders of movement?

It is impossible to say with certainty whether all ten patients have the same form of tremor without precise knowledge of the pathophysiological mechanism. However, the similarities between the three patients with jerky, tap-provoked tremor and the seven patients with continuous writing tremor seem to outweigh their differences. Thus, some patients in each group had a positive response to treatment with propranolol and alcohol; their tremors had the same frequency, and were provoked by similar actions. We suggest that these patients represent part of a spectrum of the same underlying disorder, "primary writing tremor."

It is possible that such tremor on writing may be related to several movement disorders. Writers' cramp probably is the most common complaint that causes difficulty only with the act of writing. It is often accompanied by tremulous movements of the hand, ${ }^{4-6}$ and some previous authors have classified patients with tremor on writing as having writers' cramp. ${ }^{7}$ However, none of the patients in the present study exhibited the dystonic posture of the hand typical of writers' cramp (elevation of the elbow, hyperpronation of the forearm, and forced grip of the fingers on the pen). Neither did they have any of the sustained, co-contracting muscle spasms characteristic of writers' cramp. In all these respects, these patients differed from those with writers' cramp.

Rapid rhythmic tremor-like movements also are seen in segmental myoclonus. ${ }^{89}$ But in this condition, the movements occur spontaneously and are not provoked by a special action of the hand or arm.

Tremor, then, is the primary symptom of the ten patients reported here. In the absence of any other neurological symptoms, it seems likely that such primary writing tremor represents a variant of benign essential tremor. The tremor frequency (5-6 $\mathrm{Hz}$ ) was similar, ${ }^{1011}$ as was the response of the patients to alcohol ${ }^{12-14}$ and propranolol. ${ }^{15}{ }^{16}$ One difference between the two conditions was the lack of any family history of tremor in any of the present group of patients. Not all patients with benign essential tremor report a positive family history, ${ }^{17}{ }^{18}$ so that this difference may represent a sampling bias in our group.

The cause of this condition is obscure. Three patients complained of hand injuries which preceded the occurrence of tremor, and one patient had had meningitis three years prior to onset of tremor. The other patients reported no previous illnesses. Apart from the tremor, all ten patients were entirely well.

Likewise the pathophysiology of this condition is unknown. There was no evidence of an abnormality of stretch reflex function which might be expected if 
peripheral feedback mechanisms were responsible. Yet it was observed that a peripheral stimulus, from tendon taps or muscle stretch, was capable of provoking the tremor. It is difficult to reconcile these findings, except by the suggestion that peripheral feedback may "reset" a central, internal, oscillator which is responsible for the tremor." any central defect is speculative. The only clue comes from the observation that patients with writing tremor benefit dramatically from stereotaxic thalamotomy, ${ }^{3}$ which suggests that deep structures of the brain may be involved.

We thank Mr HC Bertoya and Mr R Miller for building and maintaining the equipment used in this study. This work was supported by the Medical Research Council. JCR was a Royal Society Research Fellow.

\section{References}

' Rothwell JC, Traub MM, Marsden CD. Primary writing tremor. J Neurol Neurosurg Psychiatry 1979; 42:1106-14.

${ }^{2}$ Klawans HL, Glantz R, Tanner CM, Goetz CG. Primary writing tremor. A selective action tremor. Neurology (NY) 1982;32:203-6.

${ }^{3}$ Ohye C, Miyazaki M, Hirai T, Shibasaki T, Nakajima H, Nageseki Y. Primary writing tremor treated by stereotaxic selective thalamotomy. J Neurol Neurosurg Psychiatry 1982;45:988-97.

${ }^{4}$ Couch JR. Dystonia and tremor in spasmodic torticollis. In: Eldridge R, Fahn S, eds. Advances in Neurology. Vol 14, New York: Raven Press, 1976:245-58.

${ }^{5}$ Marsden CD. Dystonia: the spectrum of the disease. In: Yahr MD, ed. The Basal Ganglia. New York: Raven Press, 1976:351-67.
' Sheehy MP, Marsden CD. Writers' cramp-a focal dystonia. Brain 1982;105:461-80.

${ }^{7}$ Hirai T, Miyazaki M, Nakajima H, Shibasaki T, Ohye C. The correlation between tremor characteristics and the predicted volume of effective lesions in stereotaxic nucleus ventralis intermedius thalamotomy. Brain 1983; 106: 1001-18.

${ }^{8}$ Garcin R, Rondot P, Guiot G. Rhythmic myoclonus of the right arm as the presenting symptom of a cervical cord tumour. Brain 1968;91:75-84.

${ }^{4}$ Halliday AM. The neurophysiology of myoclonic jerking - a reappraisal. In: Charlton MH. ed. Myoclonic seizures, (Excerpta Medica International Congress, Series No 307). Amsterdam: Excerpta Medica, 1975: 1-29.

${ }^{10}$ Shahani BT, Young RR. Physiological and pharmacological aids in the differential diagnosis of tremor. $J$ Neurol Neurosurg Psychiatry 1976;39:772-83.

"Lee RG, Stein RB. Resetting of tremor by mechanical pertubations: a comparison of essential tremor and parkinsonian tremor. Ann Neurol 1981;10:523-31.

${ }_{12}$ Growden JH, Shahani BT, Young RR. The effect of alcohol on essential tremor. Neurology (Minneap) 1975;25:259-62.

${ }^{13}$ Rajput AH, Jamieson H, Hirsch S, Quraishi A. Relative efficacy of alcohol and propranolol in action tremor. Can J Neurol Sci 1975;2:31-5.

${ }^{14}$ Koller WC, Biary N. Effect of alcohol on tremors: comparison with propranolol. Neurology (NY) 1984; 34:221-2.

${ }^{15}$ Sweet RD, Blumberg J, Lee JE, McDowell FH. Propranolol treatment of essential tremor. Neurology (Minneap) 1974;24:64-7.

${ }^{16}$ McAllister RG. Intravenous propranolol administration: a method for rapidly achieving and sustaining desire plasma levels. Clin Pharmacol Ther 1976;20:517-23.

${ }^{17}$ Critchley M. Observations on essential (heredofamilial) tremor. Brain 1949;72:113-39.

${ }^{18}$ Marsden CD, Parkes JD. Abnormal movement disorders. Br J Hosp Med 1973;10:428-50. 